\title{
STRATEGI MEMBANGUN NATION BRANDING INDONESIA DALAM ASIAN GAMES JAKARTA- PALEMBANG 2018
}

\author{
Romi Iriandi Putra \\ Universitas Diponegoro
}

\begin{abstract}
The Asian Games 2018 is a sporting event held every 4 years, bringing together all Asian athletes from various branches to compete for the country's pride. Indonesia was chosen to be the host of the Asian games which made the right momentum to build Indonesia's nation branding. This study analyzes how the strategy of building nation branding on the momentum of Asian games 2018 Jakarta - Palembang. This research uses a descriptive qualitative method by describing related data. The results in this study show that the strategy used to build a nation branding in the Asian Games with media management, accentuate elements of Indonesian culture, conducting global diplomacy, creating mutual collaboration branding, and conducting a post events campaign. In addition to building nation branding, need several elements namely brand identity, positioning, and brand image which all focus on one goal that is to increase trading, tourism, and also an investment in the country.
\end{abstract}

\author{
Keywords \\ Asian games, nation branding, \\ place marketing, brand image, \\ destination branding.
}

Correspondence Contact 6gromil24@gmail.com

\section{PENDAHULUAN}

Pentas Olahraga Asian Games 2018 yang diselenggarakan di Indonesia, tepatnya di Kota Jakarta dan Palembang pada tanggal 18 Agustus hingga 2 September 2018 menjadi salah satu momentum tepat untuk Nasional Branding. Indonesia ditunjuk oleh OCA (Olympic Council of Asia) menjadi tuan rumah menggantikan Vietnam yang memundurkan diri dikarnakan alasan keuangan (Baihaqi, 2018). Perhelatan ajang olahraga Asia ini memiliki arti yang sangat penting bagi tuan rumah sebagai penyelenggara karena dapat dimanfaatkan sebagai nation brand dalam memperkenakan keaneka ragam budaya, kuliner dan pariwisata di Indonesia (Suryowati, 2018). Perkembangan di jaman digitalisasi sekarang memudahkan berbagai negara untuk mem-branding dirinya agar dapat dikenal oleh bangsa lain. Event yang diselenggarakan 4 tahun sekali itu dihadiri oleh atlet dari 45 negara yang melibatkan 465 pertandingan, 13.000 volunteer, 2 juta penonton, dan 11.000 media lokal dan internasional yang merupakan momentum emas untuk nation branding Indonesia.

Nation branding adalah Perpaduan unik antar elemen multidimensi yang menyediakan keragaman bangsa dengan diferensiasi dan relevansi yang berdasarkan budaya untuk semua target audience nya. Proses mem-branding suatu negara melalui bagaimana citra suatu negara dapat terbentuk, dibuat, dimonitor, dievaluasi dan dikelola secara proaktif untuk meningkatkan reputasi negara di antara wisatawan asing yang berkunjung. Selain itu juga sebagai sarana untuk mencapai keunggulan kompetitif atau meningkatkan investasi, pariwisata, pengembangan masyarakat, memperkuat identitas lokal dan identifikasi warga dengan kota mereka serta mengaktifkan semua kekuatan sosial yang ada dalam suatu negara (Fan, 2010). 
Salah satu aspek penting dalam implementasi suatu nation branding ialah slogan yang mana tiap negara memiliki tagline masing-masing sebagai representasi dari negara yang bersangkutan (Chaerani , 2011). Dalam konteks pariwisata, hal ini sangat penting terkait daya tarik bagi para wisatawan. Contohnya seperti Malaysia: truly asia, Brunei Darussalam: a kingdom of unexpected treasures, China: China like never before, Qatar: whare dreams come to life, dan Indonesia yaitu wonderful Indonesia. Tagline tersebut berdampak pada tingkat pendapatan negara terhadap wisatawan yang berkunjung ke negara tujuannya. Apabila dikaitkan dengan perhelatan ajang Asian games ini, Indonesia Organizing Committee (INASGOC) juga mengangkat slogan yakni Energy of Asia sebagai bentuk nation branding dalam event tersebut. Pemilihan kota Jakarta dan juga Palembang bukan tanpa sebab, kedua kota tersebut dinilai layak dalam menyelanggarakan event internasional sekelas Asian Games. Alasan pertama Palembang (Sumatra Selatan) layak menjadi kota penyelenggara Asian games ialah kondusifitas daerahnya yang belum pernah terjadi konflik kerusuhan antar etnis, dan umat beragama, kedua Sumatra Selatan sudah sangat berpengalaman menjadi tuan rumah berbagai gelaran event olahraga, seperti menjadi tuan rumah PON, SEA Games, Islamic Solidarity Games, Asean University Games dan masih banyak event berskala Nasional maupun Internasional yang diadakan di Sumatra Selatan, dan yang terakhir Sumatra Selatan mempunyai fasilitas yang bertaraf internasional yang lengkap bahkan terintegrasi di satu wilayah Jakabaring Sport City. Sedangkan Jakarta sendiri dipilih karena merupakan ibu kota dari Indonesia yang juga memiliki banyak fasilitas yang menunjang serta standar internasional (Rahman, 2018).

Perhelatan ajang olahraga besar sekelas Asian Games tentu akan berdampak besar terhadap Indonesia dimata Asia maupun dunia. Hal tersebut tidak lepas dari bagaimana perencanaan serta strategi yang dilakukan dari pihak-pihak yang terkait dalam mensukseskan acara yang sudah dilakukan pada bulan Agustus 2018. Pesta olahraga tersebut menjadi momentum yang tepat bagi Indonesia untuk mendapatkan eksposur dalam skala global, mendongkrak citra dan identitas bangsa, serta memperbaiki reputasi negara. Tujuannya tidak lain untuk nation branding Indonesia dimata dunia. Dari kasus tersebut peneliti tertarik untuk mengetahui bagaimana strategi membangun nation brand Indonesia dalam ajang perhelatan olahraga Asian games Jakarta - Palembang 2018. Dilihat dari seremoni pembukaan serta penutupan yang diselenggarakan Indonesia sebagai tuan rumah Asian games 2018.

\section{KAJIAN TEORITIK}

Pada dasarnya arti kara brand dan branding memiliki makna yang berbeda. Apabila brand merupakan positioning dari sebuah produk yang ada di dalam benak konsumen, berbeda hal nya dengan kata branding adalah sebuah proses dalam membangun, menciptakan dan mempertahankan brand. Konsumen akan memiliki loyalitas yang tinggi dengan cara mempromosikan value, image, dan lifestyle (Maulida, 2015).

Menurut Kavaratzis mendefinisikan nations branding sebagai: sarana untuk mencapai keunggulan kompetitif internal atau meningkatkan investasi dalam negri dan pariwisata, serta untuk mencapai pengembangan masyarakat, memperkuat identitas lokal dan identifikasi warga dengan kota mereka. Selain itu mengaktifkan semua elemen kekuatan sosial untuk menghindari pengucilan sosial. Sementara itu, citra merek, ekuitas, tujuan dan konsep-konsep berbasis pemasaran lainnya sangat berlaku untuk tempat, perbedaan mendasar terletak pada kenyataan bahwa sebuah perusahaan digerakkan oleh laba sedangkan tata kelola negara didorong oleh masyarakat itu sendiri (Kit Fok \& Yi Law , 2018).

Pada dasarnya sebuah nations branding dapat berhasil apabila dapat mengklasifikasikan beberapa faktor yang mempengaruhinya, faktor tersebut diantaranya (1) sumber daya alam, 
(2) infrastruktur umum, (3) infrastruktur wisata, (4) pariwisata dan budaya rekreasi, (5) sejarah dan seni, (6) faktor politik dan ekonomi, (7) lingkungan alam, (8) lingkungan sosial dan (9) suasana tempat itu (Nasrullah, 2012).

Sebuah pemasaran tempat atau Nations branding tidak pernah lepas dari yang namanya citra negara itu sendiri. Citra itu dapat memberikan fokus yang berbeda terhadap place marketing. Apabila sebuah tempat ataupun negara tersebut telah bergeser dari sebuah produk pasar menjadi sebuah brand, maka negara/produk tersebut menjadi sebuah objek yang dapat dinamakan identitas. Sebuah identitas merupakan instrument yang menjadi dasar branding, identitas ini menjadikan sebuah negara menjadi berbeda dari negara lain yang menjadi pesaingnya. Berikut adalah perbedaan antara identitas brand dengan citra brand:

\begin{tabular}{l|l} 
Identitas Brand & Citra Brand \\
\hline Berfokus pada source atau organisasi & $\begin{array}{l}\text { Berfokus pada penerima pesan atau audiens } \\
\text { yang menjadi target pesan }\end{array}$ \\
\hline $\begin{array}{l}\text { Dibentuk oleh aktivitas manajerial } \\
\begin{array}{l}\text { Mengalami encoding oleh brand } \\
\text { orginator }\end{array}\end{array}$ & Mengalami decoding oleh brand receiver \\
\hline Identitas dikirim & Citra diterima atau dipersepsikan \\
\hline
\end{tabular}

Sumber: (Yananda, 2014)

Langkah pertama dalam membentuk suatu citra dengan pencarian identitas itu sendiri, dikarnakan sebuah identitas suatu negara itu sangat penting maka identitas tersebut harus dicari, ditentukan, dan dikelola oleh para pemerintah setempat. Sedangkan dalam city branding terdapat empat strategi yang digunakan untuk mendorong wisatawan untuk berkunjung yaitu dengan (1) image marketing: keunikan dan kelebihan yang dimiliki suatu negara dan didukung dengan slogan masing-masing. (2) attraction marketing: berupa kekayaan dan keindahan alam yang dimiliki, bangunan, tempat bersejarah, berbagai pusat hiburan. (3) infrastructure marketing: adanya prasarana dan fasilitas pendukung kehidupan dan lingkungan bisnis yang dapat menarik investor luar. (4) people marketing: hal ini lebih mengacu kepada sikap masyarakatnya seperti keramahtamahan, pahlawan bersejarah, orangorang terkenal, dan sumberdaya manusia yang berkompeten (Intyaswono, Yulianto, \& Mawardi, 2016). Event sekelas Asian Games 2018 Jakarta - Palembang menunjukan beragam budaya dan kaarifan lokal merupakan image marketing yang dimiliki Indonesia, hal tersebut tidak lepas dari berbagai media nasional serta internasional yang menyoroti perhelatan olahraga tersebut.

\section{METODELOGI PENELITIAN}

Penelitian ini menggunakan metode deskriptif kualitatif untuk melihat bagaimana strategi membangun nation branding Indonesia dalam kasus perhelatan ajang olahraga pada Asian Games 2018 Jakarta-Palembang. Penelitian ini berfokus pada konsep branding Indonesia di mata dunia terkait sebagai tuan rumah dalam ajang Asian Games, serta melihat bagaimana strategi yang dilakukan dalam momentum perlombaan olahraga yang dilaksanakan mulai tanggal 18 Agustus sampai dengan 2 September 2018. Pada penelitian ini juga menganalisis secara deskriptif konseptual terkait strategy of destination branding, konsep identitas, positioning, dan citra brand Indonesia sebagai tuan rumah perhelatan akbar Asian Games 
tersebut. Selain itu juga pada kasus ini dapat mendeskripsikan sesuai konsep strategi dari ajang pembukaan serta penutupan dalam Asian Games 2018.

\section{HASIL DAN PEMBAHASAN}

\section{Strategi Indonesia dalam Momentum Asian Games}

Berdasarkan hasil analisa peneliti terkait strategi yang digunakan Indonesia dalam mengambil kesempatan di momentum yang sangat tepat yaitu perhelatan ajang olahraga Asian Games 2018 Jakarta-Palembang, perlombaan olahraga ini membawa dampak yang sangat besar bagi Indonesia dalam mengenalkan segala kekayaan yang dimilikinya dimata dunia. Berikut ada beberapa strategi yang dilakukan Indonesia selama Asian Games:

a. Mengelola paparan media. Ajang Asian games memunculkan beragam berita baik yang bagus ataupun tidak mengenai Indonesia pasti akan ter-blowup ke media yang mana berdampak terhadap citra dan reputasi Indonesia di mata dunia.

b. Mengangkat semua unsur budaya yang dimiliki. Hal demikian dapat dilihat melalui opening ceremony yang dilaksanakan di Glora Bung Karno (GBK) dengan membawa kebinnekaan budaya Indonesia ke panggung dunia. Disana menampilkan pertunjukan lengkap 19 tarian dari penjuru barat hingga ke arah timur Indonesia, diantaranya ialah tari Ratoh Jaroe Aceh yang kolosal, Lenong Betawi, Jaipongan, Saman, hingga tari Yospan Papua.

c. Diplomasi global dari ajang Asian games. Pada kesempatan ini Indonesia juga memanfaatkan Asian games untuk berjuang menjadi salah satu negara yang memiliki kekuatan ekonomi serta negara demokratis terbesar di dunia.

d. Menciptakan Co-branding. Melihat kasus dari opening ceremony yang memukau disini bisa dikatakan bahwa kehebatan brand dari Asian games tersebut dibantu oleh Indonesia untuk mengangkat citra brand masing masing.

e. Post event campaign. Hal ini bagaimana Indonesia harus melakukan kampanye terkait bidang trading, tourism, dan juga investment (TTI).

Selain dari beberapa strategi di atas, ada beberapa alasan pembentukan nation branding Indonesia dalam memanfaatkan ajang Asian games yaitu Global visibility yang mana pelaksanaan Asian games selama 2 minggu tersebut disorot banyak media, tidak hanya sebagai tuan rumah yang bertanggung jawab terkait kesuksessan acara akan tetapi juga peran masyarakat, ragam budaya, keindahan alam, infrastruktur serta kekayaan kulinernya. Momentum tersebut juga sebagai Nation brand identity yang mana dapat memperkenalkan karakter bangsa, etnis, suku, sejarah, dan keramahtamahan masyarakat Indonesia. Apabila dilihat dari efek pembukaan Asian games tersebut dapat menjadi brand story of the nation terhadap pengunjung internasional. Yang terakhir sebagai rebranding \& repositioning Indonesia disaat bangsa ini masih banyak mengalami musibah dan bencana, seperti pada pelaksanaan Asian games yang mana pada saat itu daerah Lombok mengalami bencana gempa bumi yang mengakibatkan jatuhnya beberapa korban jiwa. Akan tetapi Indonesia tetap menunjukan kapabilitas sebagai tuan rumah Asian games untuk mensukseskan acara tersebut.

Apabila dilihat dari hasil perolehan citra Indonesia yang menjadi tuan rumah Asian games 2018 memberikan dampak yang cukup signifikan. Menurut hasil rilis dari Kementrian PPN/Bappenas dampak langsung penyelenggaraan Asian games terhadap ekonomi DKI Jakarta kurang lebihnya mencapai Rp. 22,1 triliun. 


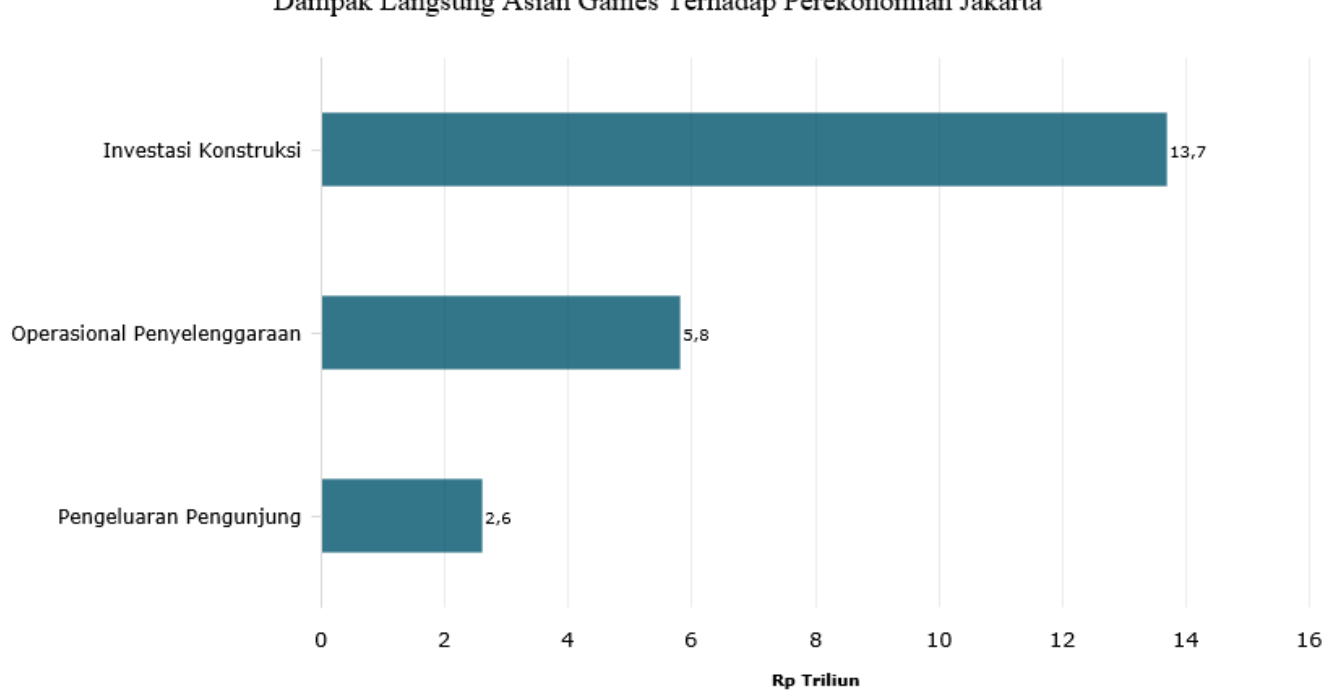

Selain berdampak pada perekonomian negara, Asian games juga memberikan lapangan pekerjaan bagi masyarakat sekitar. Hal tersebut juga dirilis oleh Kementrian PPN/Bappenas yang mana perhelatan tersebut memberikan peluang kesempatan pada sekitar 57.300 orang sepanjang tahun 2015-2018. Rata-rata peningkatan kesempatan kerja yang diberikan dalam ajang tersebut mencapai $0,51 \%$ pada tahun 2018-2019. Sama hal nya dengan provinsi Sumatra Selatan, dampak yang dirasakan pada perekonomian nya mencapai Rp. 18,5 triliun. Investasi konstruksi menyumbang sebesar Rp. 15,4 triliun, oprasional penyelenggaraan Rp. 2,1 triliun, dan pengeluaran pengunjung sebesar Rp. 968 miliar. Asian games memberikan dampak positif terhadap sektor pariwisata seiring datangnya para atlet dari berbagai macam negara (Databox, 2018).

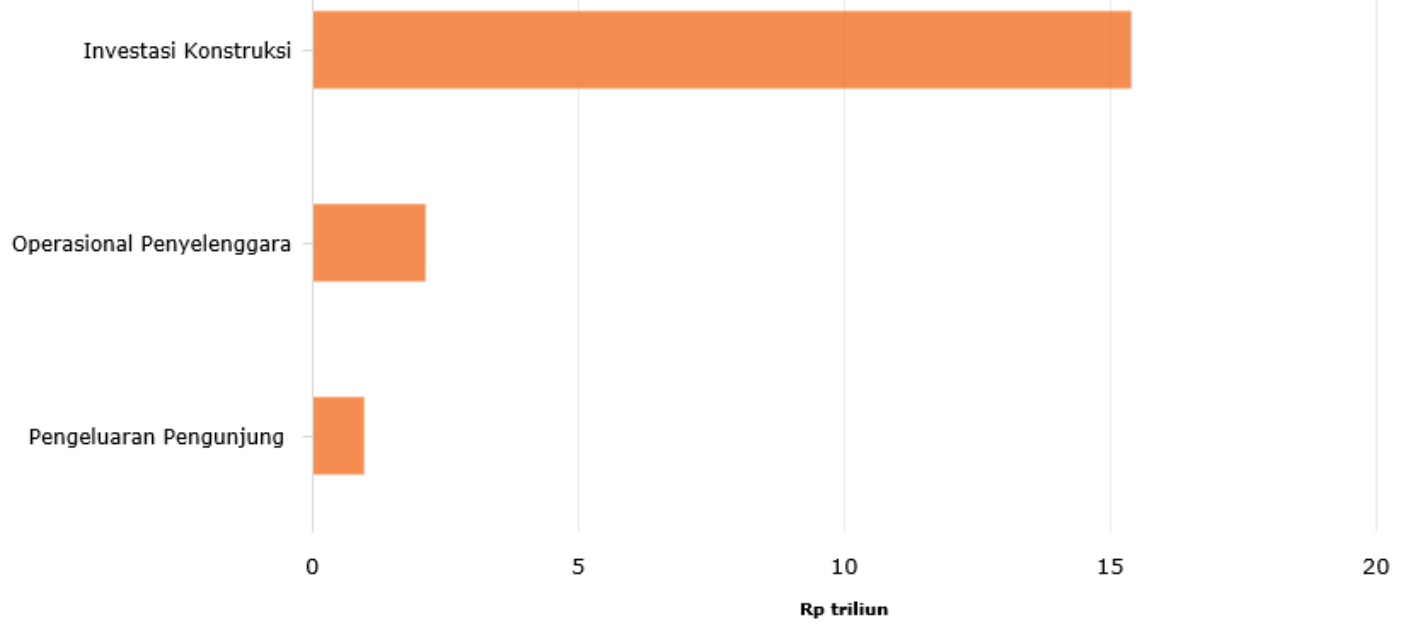

Pengaruh yang diberikan oleh momentum Asian games tidak semata-mata terjadi begitu saja, melainkan ada keterlibatan beragam lapisan masyarakat, pemerintah serta panitia yang menyelenggarakan acara tersebut. Peran tersebut juga di tunjukan oleh presiden Joko Widodo yang memiliki strategi sendiri dalam mempromosikan Asian games 2018 sebelum acara 
tersebut dimulai. Beliau menggunakan jaket Asian games pada saat menerima perwakilan siswa dan siswi OSIS SMA berprestasi se-Indonesia di istana Bogor. Hal tersebut menjadi salah satu peran dan strategi presiden dalam mensukseskan dan membangun brand identity dari ajang Asian games tersebut.

\section{Asian Games sebagai Nation Branding Indonesia}

Perhelatan ajang olahraga Asian Games 2018 menjadi salah satu ajang dalam mendongkrak citra Indonesia dimata dunia melalui paparan media yang ditayangkan. Indonesia Organizing Committee (INASGOC) juga mengkonfirmasi bahwa mega-sporting event tersebut diliput oleh kurang lebih sebelas ribu media luar dan dalam negeri. Hal tersebut menjadi momentum yang sangat tepat bagi Indonesia untuk memperkenalkan citra dan beragam budaya yang dimilikinya. Pembentukan citra dan juga brand suatu negara dapat dilihat dari enam dimensi (Yuswohady, 2018) Yakni:

a. Dimensi export, yang melihat dari persepsi masyarakat internasional terkait produk serta pelayanan yang disediakan oleh INASGOC sebagai panitia penyelenggara Asian games 2018.

b. Dimensi governance, terkait persepsi masyarakat internasional tentang kemampuan negara dalam mengelola pemerintahan yang professional dan demokratis. Ajang Asian games tersebut juga didukung oleh pemerintah Indonesia khususnya bagi kota yang menjadi penyelenggara acara yaitu Jakarta dan juga Palembang.

c. Dimensi culture dan heritage, dilihat dari persepsi masyarakat internasional tentang keragaman budaya suatu negara seperti seni budaya, sastra, dan juga musik-musik tradisonal. Di sisi lain, logo yang dibuat dalam ajang Asian games tersebut juga menunjukan banyak sekali unsur budaya yang terdapat di Indonesia seperti Bhin Bhin si Cendrawasih yang menggambarkan pulau paling timur Indonesia yakni papua yang terkenal akan keindahan alamnya, Atung Rusa Bawean yang menggambarkan mahkluk hidup endemic dari Bawean Gresik Jawa Timur, dan yang terakhir ialah Kaka si Badak Jawa yang memiliki habitat paling luas di Indonesia. Apabila dikaitkan dari ketiga logo tersebut bermakna kepintaran (bhin bhin), kecepatan (atung), kekuatan (kaka) yang menggambarkan semboyan negara Bhineka Tunggal Ika.

d. Dimensi people, dimensi ini juga berkaitan tentang persepsi masyarakat internasional terkait kualitas sumber daya manusia yang dimiliki seperti kompetensi, etika prilaku dan keterbukaan.

e. Dimensi selanjutnya yakni tourism, didimensi ini yang menjelaskan bagaimana ketertarikan wisatawan mancanegara terhadap negara Indonesia dikarnakan aneka ragam budaya, etnis, keindahan alam serta destinasi wisata yang disediakan.

f. Dimensi investment dan immigration, yang mana negara memiliki kemampuan untuk menarik wisatawan untuk berinvestasi, tinggal dan belajar di Indonesia.

Dari 45 negara yang ikut serta dalam ajang Asian games tersebut, ada 5 negara yang mendatangkan pengunjung mancanegara terbanyak ke Indonesia diantaranya ialah dari negara Tiongkok sebanyak 10.375, Jepang 10.038, Korea sebanyak 7.443, Malaysia 5.244, dan negara India sebanyak 5.001 wisatawan. Apabila dilihat dari kajian nation branding, kesempatan ini menjadi titik awal mempromosikan Indonesia lewat ajang olahraga yakni Asian games 2018 lalu (Muslimmah, 2018).

Nation branding ialah sebuah realitas kompleks dari sebuah negara dengan merangkum budaya, masyarakatnya, sejarah yang dimiliki dan unsur-unsur keunggulan yang dimiliki negara yang nantinya akan memberikan sebuah positioning dan juga differentiation dari brand tersebut. Selain itu juga nation branding bertujuan untuk memnciptakan sebuah citra 
dan reputasi suatu negara di mata penggunjung mancanegara, dan citra inilah yang memberikan sebuah image yang mana baik itu positif maka wisatawan akan tertatik dengan sendirinya untuk berkunjung ke negara tersebut (Utami \& Gaffar, 2016). Selain itu, manfaat nation branding yang dirasakan untuk negara-negara berkembang dari menjadi tuan rumah acara-acara olahraga adalah banyaknya negara berkembang telah mengambil risiko besar dalam bertaruh bahwa tuan rumah acara-acara besar dapat menjadi jalur cepat untuk pengakuan dunia dan peningkatan reputasi, dan ada bukti yang cukup bahwa taruhan ini memiliki dampak positif pada citra dan reputasi negara sebagai produsen produk dan sebagai tujuan wisata. Profil media besar dari event tersebut dapat dimanfaatkan untuk meningkatkan kesadaran, keunggulan dan kedudukan tempat serta berfungsi sebagai agen perubahan dalam hal citra dan makna suatu negara.

Hal lain juga ditunjukan oleh Indonesia sebagai tuan rumah Asian Games saat pembukaan seremony Asian Games di Stadiun Glora Bung Karno yang menunjukan beragam kebudayaan, tarian, etnis, suku, serta keaneka ragam busana khas nusantara yang dimiliki Indonesia dari Sabang sampai Marauke. Tidak lupa pula peran Joko Widodo sebagai kepala negara yang tampil memukau seluruh pengunjung Stadiun Glora Bung Karno. Keterlibatan presiden Joko Widodo dalam penayangan opening seremony Asian Games memunculkan persepsi bahwa bagaimana solidnya pemerintahan yang ada di Indonesia untuk mensukseskan acara tersebut. Begitu pula dengan seremony penutupan yang diwakilkan oleh Jusuf Kalla sebagai wakil presiden yang menjadi salah satu bentuk dedikasi pemerintah Indonesia sebagai tuan rumah Asian Games. Kesuksesan perhelatan Asian games yang dilaksanakan di Jakarta-Palembang tidak lepas dari persiapan, perencanaan serta strategi yang dijalankan. Momentum tersebut juga jadi ajang membangun identitas negara Indonesia di mata dunia. Hubungan identity, positioning dan brand image menjadi dasar membangun nation branding Indonesia sebagai tuan rumah. Konsep yang dipakai dalam pembentukan identitas di gambarkan melalui hubungan antara ketiga unsur tersebut:

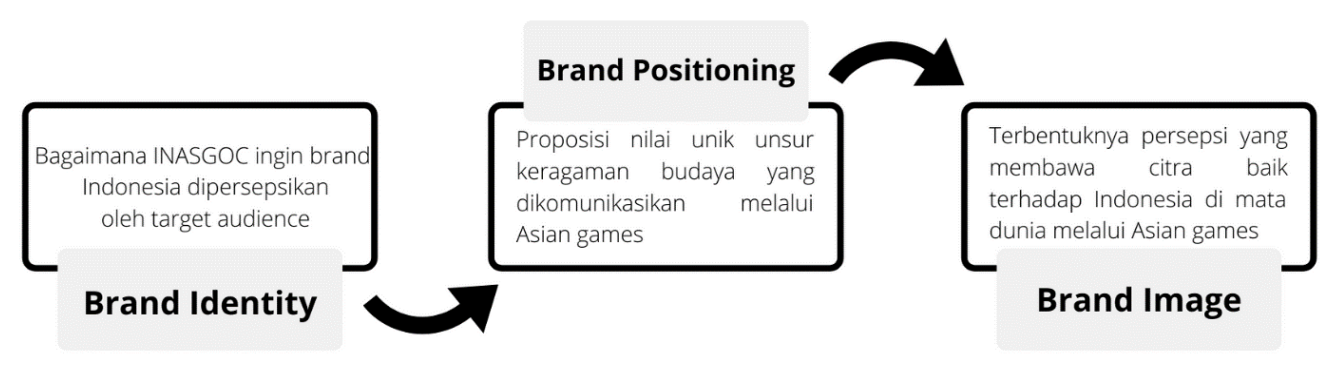

Kavaratzis \& Ashworth dalam Yananda (2014)

Kekuatan yang dihadirkan Asian games menjadikan tuan rumah yakni Indonesia mengambil kesempatan untuk memperkenalkan negara beserta unsur kekayaan yang dimiliki kepada seluruh pengunjung yang datang. Ketiga unsur di atas pun menjadi dasar pedoman yang dilakukan INASGOC, tidak hanya mensukseskan acara Asian games saja akan tetapi main goals nya ialah bagaimana kehebatan Indonesia dengan keragaman budayanya dapat dilihat oleh negara-negara yang datang bahkan dimata dunia.

Kesuksesan seremony pembukaan serta berjalannya ajang Asian games sampai penutup tidak lepas dari bagaimana membangun konsep-konsep yang menarik, sehingga membuat pengunjung yang datang terkesima akan kekayaan dan keberagaman budaya yang dimiliki Indonesia. Konsep yang diambil dengan memperkenalkan budaya dari Sabang hingga Marauke tidak lain dengan tujuan memberikan pengalaman lebih terhadap pengunjung dan 
membangun destination branding. Langkah pertama dalam membangun destination branding ialah dengan melakukan pemasaran tempat. Place marketing ialah suatu aspek dari sebuah pembangunan perkotaan. Pembangunan tersebut memiliki beberapa elemen dari pengembangan layanan masyarakat, desain dan perencanaan kota, pengembangan ekonomi, dan strategi perencanaan pasar (Yananda \& Salamah, 2014). Selain itu, place branding juga menjadi hal yang selanjutnya dari langkah dalam membangun destination branding. Keunikan, keindahan alam, keberagaman budaya serta kekayaan kulinar khas nya menjadi poin-poin yang penting untuk dikembangkan. Semua unsur tersebut dapat membentuk persepsi terhadap pengunjung yang datang hingga pada akhirnya memberikan sebuah pengalaman yang baik di benak wisatawan.

Membangun sebuah nation branding tidak semata-mata hanya untuk mensukseskan ajang Asian games 2018 saja, akan tetapi seluruh lapisan dan sektor-sektor yang ada di Indonesia, contohnya sektor ekonomi, pariwisata, kuliner dan juga investasi. Apabila dilihat melalui strategi komunikasi pemasaran pariwisata, hal yang dilakukan dalam momentum Asian games itu ialah dengan menerapkan pull strategy. Strategi komunikasi pemasaran pariwisata yang tujuan nya ialah untuk menarik dan meningkatkan kesadaran pengunjung. Ajang Asian games menjadi media penyaluran nation branding sekaligus meningkatkan kesadaran wisatawan/pengunjung dalam menyaksikan perlombaan yang dilaksanakan di Jakarta dan juga Palembang.

\section{KESIMPULAN}

Seluruh perhelatan olahraga baik skala benua Asia ataupun sekelas piala dunia tidak lepas kaitannya dengan nation branding negara yang menjadi tuan rumah. Hal tersebut juga dimanfaatkan Indonesia sebagai tuan rumah Asian Games 2018 yang dilaksanakan di kota Jakarta - Palembang. Memperkenalkan Indonesia melalui ajang olahraga dan membangun kesadaran para pengunjung hingga dapat mempersepsikan Indonesia dengan segala kekayaan yang dimiliki menjadi sebuah brand image bagus untuk perkembangan semua sektor yang ada di negara ini. Memberikan experience yang tidak pernah didapat sebelumnya menjadikan metode pemasaran word of mouth lebih efektif. Keberhasilan Indonesia sebagai tuan rumah dalam ajang Asian games 2018 tidak terlepas dari persiapan yang cukup, promosi, pelayanan infrastruktur yang sesuai standar internasional, dan juga keterlibatan masyarakat serta pemerintah nya menjadi kunci utama. Semua unsur di atas itu tidak lain untuk membangun nation branding Indonesia. Setelah mega event tersebut, Indonesia pun dipercaya kembali menjadi tuan rumah ajang piala dunia under 22th digelar pada tahun 2021, yang mana akan menjadi momentum nation branding untuk Indonesia.

\section{DAFTAR PUSTAKA}

Baihaqi, B. (2018, Mei Kamis). Inasgoc Asian Games 2018 Harus Jadi National Branding. Retrieved from Harian Ekonomi Neraca: http://www.neraca.co.id/article/100725/inasgoc-asian-games-2018-harus-jadinational-branding

Chaerani , R. Y. (2011). Pengaruh City Branding Terhadap City Image (Studi Pencitraan Kota Solo: 'The Spirit of Java').

Databox. (2018, Juli Selasa). Asian Games 2018 Menyumbang Rp 19 Triliun Bagi Perekonomian Sumatera Selatan. Retrieved from Katadata.com: https://databoks.katadata.co.id/datapublish/2018/07/31/asian-games-2018menyumbang-rp-19-triliun-bagi-perekonomian-sumatera-selatan 
Fan, Y. (2010). Branding The Nation: Towards A Better Understanding. Cities.

Intyaswono , S., Yulianto, E., \& Mawardi, M. K. (2016). Peran Strategi City Branding Kota Batu Dalam Trend Peningkatan Kunjungan Wisatawan Mancanegara. Jurnal Administrasi Bisnis.

Kit Fok, K. W., \& Yi Law , W. W. (2018). City re-imagined: Multi-stakeholder study on branding Hong Kong as a city of greenery. Journal of Environmental Management.

Maulida, D. (2015). Tourism Destination Branding: Analisis Strategi Branding Wisata Halal "The Light Of Aceh".

Muslimmah, A. (2018, Oktober Rabu). Inilah Wisman Terbanyak yang Datang ke Asian Games 2018. Retrieved from Kompas.com: https://travel.kompas.com/read/2018/10/17/140700927/inilah-wismanterbanyak-yang-datang-ke-asian-games-2018?page=all

Nasrullah, R. (2012). Komunikasi Antar Budaya (DI Era Budaya Saiber). Jakarta: Kencana Prenadamedia Group.

Noni, I. D., Orsi, L., \& Zanderighi, L. (2019). Stereotypical versus experiential destination branding: The case of Milan city. City, Culture and Society, 38-45.

Rahman, A. (2018, Mei Sabtu). Tiga Alasan Sumsel jadi Tuan Rumah Asian Games 2018. Retrieved from INDOPOS: https://indopos.co.id/read/2018/05/05/136989/tigaalasan-sumsel-jadi-tuan-rumah-asian-games-2018/

Rynaldi, M. J. (2018). Glosarium Sepak Bola Asian Games. Jakarta: FANDOMENULIS.

Suryowati, E. (2018, Mei Minggu). Indonesia Dapat Kesempatan Promosi Budaya Lewat Asian Games. Retrieved from JawaPos.com: https://www.jawapos.com/ekonomi/bisnis/13/05/2018/indonesia-dapatkesempatan-promosi-budaya-lewat-asian-games/

Utami, S., \& Gaffar, V. (2016). Pengaruh Strategi Nation Branding "Wonderful Indonesia" Terhadap Proses Keputusan Berkunjung Wisatawan Australia Ke Indonesia. The Journal : Tourism and Hospitality Essentials Journal, 693.

Yuswohady. (2018, September Senin). Brand Indonesia dan Asian Games. Retrieved from Alinea.id: $\quad$ https://www.alinea.id/kolom/brand-indonesia-dan-asian-gamesb1U539d5K 